ARTIGO

Recebido em: 15/07/2015

Aceito em: $28 / 09 / 2015$

\title{
As políticas de direitos autorais e de reuso presentes nas revistas brasileiras de acesso aberto das áreas biológicas e de saúde disponibilizadas na plataforma SciELO-Brasil \\ Author rights and re-use policies in Brazilian open access journals in the biological and health sciences available on the SciELO-Brazil platform
}

\author{
Ariadne Chloe Mary FURNIVAL \\ Professora do Departamento de Ciência da Informação, Universidade Federal de São Carlos/UFSCar - \\ chloeufscar@gmail.com
}

\section{Bianca Miranda de ALMEIDA}

Bibliotecária e Coordenadora do Sistema de Bibliotecas do Centro Universitário UniSEB/Ribeirão Preto - biancamialm@hotmail.com

Marco Donizete Paulino da SILVA

Bacharel em Biblioteconomia e Ciência da Informação pela Universidade Federal de São Carlos-UFSCar, Mestre e Doutorando em Ciência, Tecnologia e Sociedade pela Universidade Federal de São Carlos/UFSCar - marco donizete@yahoo.com.br

\section{Resumo}

0 termo Acesso aberto se refere à disponibilização online, gratuita e livre de restrições, da literatura científica. No Brasil, essa dinâmica se dá, majoritariamente, através das revistas em Acesso Aberto, a chamada "via dourada". A publicação de tais revistas tem crescido continuamente desde a abertura da plataforma SciELO no Brasil, em 1997, e do sistema OJS pelo IBICT. Apesar da ampla divulgação mundial dos conceitos e definições sobre Acesso Aberto, e, sobretudo, em relação a questões de Direitos Autorais, autorização de reuso e arquivamento em repositórios, a hipótese aqui levantada é de que ainda existem situações conflitantes nas políticas de algumas revistas brasileiras de Acesso Aberto, conflitos relativos aos Direitos Autorais e aos direitos de reuso pelos leitores-usuários-autores. 0 artigo relata um estudo que teve como objetivo principal analisar e averiguar o conceito de Acesso Aberto, explícita e implicitamente usado nas revistas levantadas, sinalizando, de certa forma, o grau de "abertura" destas, tal como definido recentemente no folheto "HowOpenIsIt?" publicado por SPARC, PLoS e OASPA. Foram estudadas as políticas de Direitos Autorais de uma amostra composta por 117 periódicos correntes da área das Ciências Biológicas e Ciências de Saúde na plataforma SciELO-Brasil. Os resultados demonstram que existe uma variedade de apropriações e significações do termo "Acesso Aberto" que se manifestam na redação da política dos Direitos Autorais de tais revistas, dando espaço para confusões entre autores e leitores no que se refere aos direitos de reuso e disseminação posteriores à publicação, direitos estes intrínsecos às definições "clássicas" de Acesso Aberto.

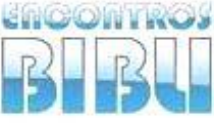

v. 20, n. 44,2015 p. $25-42$

ISSN 1518-2924

Palavras-Chave: Revistas em Acesso Aberto. Direitos autorais. Copyright. Direitos de reuso. SCiELO. DOAJ.

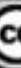




\begin{abstract}
Open access refers to the free availability of scientific publications online, and free of restrictions, and is in Brazil, predominantly achieved by the so-called "gold route" of open access, that is, open access journal publication. The quantity of these publications has grown continuously since the launch of the SciELO platform in Brazil in 1997, and the 0JS system promoted by IBICT. Despite the worldwide dissemination of open access concepts and practices, particularly in relation to copyright and authorization for reuse and archiving in repositories, the hypothesis raised here is that there are still conflicting positions in policies of some Brazilian open access journals regarding copyright re-use by reader-users. The paper reports a study that aimed to analyze and investigate the concept of open access explicitly and implicitly used in the set of journals studied, to assess their degree of "openness", as recently defined in the pamphlet "HowOpenIsIt?" published by SPARC, PloS and OASPA. Copyright policies were studied in a sample of 117 current journals in the fields of Biological and Health Sciences from SciELO- Brazil. The results show that there is a variety of appropriations and meanings of the term "open access" by the journals assessed, manifested chiefly in the periodicals' copyright policy. This variety gives room for confusion regarding reuse and author rights, such rights being intrinsic to strong definitions of open access.
\end{abstract}

Keywords: Open Access Journals. Author rights. Copyright. Reuse rights. SciELO. DOAJ.

\title{
1 INTRODUÇÃO
}

A expressão Acesso Aberto (Open Access) se refere à modalidade de publicação que visa disponibilizar a literatura científica online, gratuitamente e livre de restrições. A motivação por trás da ampla promoção dessa forma de publicação científica é que a pesquisa básica e aplicada é majoritariamente financiada pelos governos com a expectativa de que, ao compartilhar e difundir as novas ideias e descobertas resultantes de tal pesquisa, a ciência e tecnologia progredirão de modo mais rápido e eficiente, sem duplicações desnecessárias, o que por sua vez, melhorará a vida dos indivíduos e o bem estar da sociedade como um todo (GUIBAULT, 2011; RODRIGUES, 2004).

Mesmo que o movimento de Acesso Aberto tenha se difundido globalmente desde a sua incepção em 2002, alguns autores observam a ironia de que, justamente no momento em que as tecnologias de informação e comunicação (TIC) permitem maior acesso à produção científica e criativa assim como crescimento de seu uso -, existe o movimento de fortalecer o arcabouço de restrições que aprisionam e protegem o conteúdo digital de maneira que nunca teríamos imaginado em relação ao material impresso (MONBIOT, 2011). As referidas restrições de acesso se manifestam em formas de copyright, direitos autorais e direitos de reuso, uma tríade que constitui, conjuntamente, o tema central do presente artigo, relatando os resultados de uma pesquisa que objetivou averiguar, numa amostra de revistas brasileiras de Acesso Aberto, a compatibilidade entre a aplicação dos direitos autorais e os direitos de reuso nas mesmas - como evidenciado nas capas destas revistas e em suas políticas e procedimentos de submissão. A pesquisa foi impulsionada pelo ensejo de testar a hipótese de que não existe, mesmo nas revistas de Acesso Aberto, clareza acerca da administração dos direitos autorais e de reuso que o autor do artigo detém.

0 auto-arquivo em repositórios digitais descreve o que é conhecido como a "via verde" do Acesso Aberto, que consiste na rede mundial, crescente e interoperável, de repositórios digitais, vertente que se compara com a 
outra, a "via dourada" do Acesso Aberto, constituída pela criação, gestão e disseminação de revistas científicas que "nascem digitais" e, também, em termos da sua disseminação, nascem como publicações em Acesso Aberto.

0 OpenDOAR - um diretório internacional de repositórios digitais em Acesso Aberto -registra, atualmente, apenas 85 repositórios de Acesso Aberto no Brasil (http://www.opendoar.org/find.php), o que talvez torne inegável que, comparativamente, a "via dourada" de Acesso Aberto esteja bem mais consolidada em território brasileiro, com uma quantidade formidável de revistas científicas disponíveis em Acesso Aberto, ocupando o segundo lugar no mundo, com 937 revistas registradas no Directory of Open Access Journals (DOAJ), somente atrás dos Estados Unidos, que ocupam o primeiro lugar no mesmo Diretório, com 1218 revistas em Acesso Aberto (DIRECTORY..., 2014).

Pode se afirmar que o grande responsável para este fortalecimento da "via dourada" no Brasil, comparada com a "via verde", ainda em estado incipiente, é a plataforma SciELO - Scientific Electronic Library Online, lançada em 1997 como um programa especial da Fundação de Amparo à Pesquisa do Estado de São Paulo (FAPESP), em parceria com a BIREME (Centro Latino-Americano e do Caribe de Informação em Ciências da Saúde). Como o próprio idealizador da SciELO, Abel Packer, observa, a motivação principal da SciELO é dar visibilidade mundial à "ciência perdida", mas muito valiosa, originada nos países em desenvolvimento, os quais, por vários motivos, sempre enfrentaram grandes obstáculos para publicar em canais de publicação prestigiosos, como os das revistas científicas dos países centrais.

Observa-se que a SciELO não se reduz a uma plataforma, repositório ou portal de acesso às revistas nela contidas: consiste também numa concepção e metodologia de editoração e publicação científica que garantem a qualidade das publicações disponibilizadas pelo ambiente SciELO, derivando padrões de alta qualidade que lhe tem granjeado uma posição louvável em que vários dos índices bibliográficos internacionais e regionais (incluindo o Web of Science, Scopus, CROSSREF, Google Scholar, PubMed, LILACS, AGRIS, DOAJ) que mantém links atualizados para as revistas da SciELO - o que tem contribuído para o crescimento do Fator de Impacto de vários títulos ali disponibilizados. Em julho de 2012 a SciELO foi integrada no Web of Knowledge da Thomson Reuters, considerando-se válido ressaltar que, desde a sua incepção, o programa da SciELO priorizou a disponibilização de suas revistas online e, como Packer (2009) observa, logo se percebeu que o caminho de Acesso Aberto era o caminho mais certo a se seguir.

Também se considera pertinente observar que, fora da América Latina, existem editoras extremamente respeitadas que publicam somente em Acesso Aberto, a Public Library of Science (PLoS) e a Biomed Central são exemplos destas, publicando artigos originais em Acesso Aberto, principalmente na literatura STM (Science, Technology \& Medicine). Os desafios para essas editoras se referem à compatibilização entre o modelo de sustentabilidade financeira que utilizam e o estabelecimento de uma boa reputação que influa no fator de impacto da revista, ou, mais comumente na época atual, nas métricas alternativas - as "altmetrics" - dos downloads de artigos individuais. 
No que concerne aos autores, estes procuram veículos de publicação que otimizem a disseminação do seu trabalho na comunidade de pares para que seu trabalho possa ser debatido, avaliado e usado como base para futuros avanços, além de fortalecerem sua reputação dentro da comunidade científica. Existem vários levantamentos que demonstram, infelizmente, a falta de consciência dentro da comunidade científica de que tais metas podem, sim, ser alcançadas via a publicação em Acesso Aberto.

Os modelos de negócios em Acesso Aberto do tipo "o autor paga" têm sido interpretados, na mente de pesquisadores, com publicações de qualidade inferior. Cabe mencionar aqui que muitas das editoras comerciais tradicionais (por exemplo: Springer Open Choice Publishing, Nature Open), que operam predominantemente sob o modelo de assinatura, também oferecem a "opção aberta" de publicação: ou seja, no mesmo volume e número de uma determinada revista, se encontram artigos em Acesso Aberto ao lado de artigos "fechados", simplesmente porque o autor (sua universidade ou o órgão de fomento à pesquisa realizada) pagou para que o artigo pudesse ser disponibilizado em Acesso Aberto, imediatamente à sua finalização.

Morrison (2009) enfatiza que é importante desmistificar a noção de que toda publicação OA (Open Access) cobre uma taxa para a publicação: a autora cita um estudo de Hooker, de 2007, que demonstrou que $67 \%$ das revistas listadas no DOAJ não cobram pela publicação, citando, também, um estudo de Suber e Sutton (2007) no qual se demonstra que 83\% das editoras $\mathrm{OA}$ de sociedades e associações científicas não cobram taxas de processamento de artigos. Suber (2012) observa que a maior parte das revistas em acesso segue as políticas editoriais e práticas das revistas convencionais, e de fato, o rigor do processo de editoração e publicação de revistas em Acesso Aberto não deveria ser colocado em questão, como os altos padrões exigidos pelos títulos da SciELO atestam.

\section{GRAUS DE “ABERTURA”}

As revistas em Acesso Aberto tem a característica evidente de que são facilmente acessíveis para o leitor, mas o que se pauta aqui é que ser "aberto" significa apenas isso: ser facilmente acessível online? Os idealizadores e mantenedores do prestigioso e muito consultado Directory of Open Acess Journals (DOAJ) lançam mão da definição seminal e "forte" de Acesso Aberto, consagrada na Declaração da Budapest Open Access Initiative (BOAI) de 2002, afirmando que:

Da definição BOAI de "Acesso Aberto", apoiamos os direitos dos usuários a "ler, fazer download, copiar, distribuir, imprimir, realizar buscas em, ou linkar aos textos completos desses artigos" como mandatórios/obrigatórios para que uma revista seja incluída no Diretório (DIRECTORY..., 2014, tradução nossa).

Mas ao que parece, essa definição "clássica” e "holística” de Acesso Aberto não tem sido unânime e conscientemente abraçada por editores, 
autores, pesquisadores, pois, existe um espectro variado de permissões, declarações de copyright, cessão de direitos autorais, etc., vinculado às publicações disponíveis em plataformas como a SciELO e, inclusive, cadastradas no próprio DOAJ.

A questão, no que concerne o grau de "abertura" de material disponível em Acesso Aberto é, discutivelmente, tão nebulosa que um conglomerado de organizações engajadas na promoção da publicação científica em Acesso Aberto - o SPARC, PLoS e OASPA - recentemente publicaram um folheto intitulado "QuãoAbertoÉ?" - "HowOpenIsIt?" (disponível em: http://www.sparc.arl.org/resource/howopenisit) - que esquematiza sucintamente atributos e critérios que podem ser usados para julgar se um dado documento pode ser caracterizado, factualmente, como de "Acesso Aberto". 0 intuito do panfleto é o de ir além da ideia de que o Acesso Aberto se refere apenas à "gratuidade de acesso para todos os leitores" que utilizam a internet: sua intenção é de recuperar e revitalizar as dimensões do conceito de Acesso Aberto como definido originalmente na BOAI, ou seja, dimensões que também se referem aos direitos de uso e reuso, além de esclarecer para os autores-pesquisadores quais são seus direitos se a publicação for realmente classificada como sendo de "Acesso Aberto".

Diante do panorama esboçado nos parágrafos anteriores, o estudo aqui descrito - realizado em escala modesta - teve como objetivo geral averiguar quão abertas são as revistas de Acesso Aberto, numa amostra produzida a partir da coleta de revistas disponibilizadas na base SciELO. Os objetivos específicos foram os de: identificar se a revista em análise era veiculada sob uma licença Creative Commons, assim como seu grau de explicitação do tipo de direito de reuso; identificar se a revista estava indexada no DOAJ (sendo assim classificada como uma revista de Acesso Aberto); estabelecer se a política editorial requeria a cessão dos direitos autorais à revista no processo de submissão do manuscrito (o que, consequentemente, determinará a liberdade de reuso do autor, possibilitando-lhe a disponibilização do artigo num momento póspublicação).

Salienta-se que os direitos que o autor detém em relação a um artigo seu determinarão o que esse autor poderá fazer com o mesmo após sua publicação na revista de Acesso Aberto. Ou seja, quais são os direitos de reuso do artigo por esse autor, nos quais se incluem o seu direito de autoarquivar uma cópia do trabalho num repositório digital, por exemplo - a passagem da "via dourada" para a "via verde". Cabe ressaltar que os mesmos questionamentos se aplicam à passagem da publicação de um artigo numa revista "fechada", de assinatura, para seu depósito ou autoarquivamento num repositório em Acesso Aberto. A base de dados SHERPA-RoMEO fornece informações sobre as políticas de copyright e de autoarquivo das editoras, mas a mesma explicita que não verifica as políticas das revistas Acesso Aberto registrados como tal no DOAJ. Explica que:

A maior parte das revistas de Acesso Aberto também permitem o autoarquivo e a reutilização, mas algumas, não. Não se assume que o autoarquivo é permitido, a não ser que tenha sido publicado sob uma licença Creative Commons." (SHERPA-RoMEO, 2014). 
São estes aspectos das políticas de revistas Acesso Aberto que são o foco do presente artigo, e aos quais retornaremos ao apresentar alguns resultados do estudo realizado, considerando-se pertinente ainda observar que, embora as realidades do campo editorial - sobretudo os processos editoriais das revistas científicas - sejam relacionadas com o estudo ora proposto, não são essas realidades o foco de nossa investigação (intenção improvável de êxito pela limitação do espaço e tema discutidos em nossa abordagem: a característica do Acesso Aberto como proposta de disponibilização de conteúdos autorais e sua explicitação como aspecto factualmente colocado em prática nas páginas das revistas analisadas).

Nessas condições, observa-se, pelas proposições de Ferreira e Targino (2005) em torno dos processos e procedimentos exigidos na manutenção do campo de editoração/publicação das revistas científicas, a presença de variados aspectos tanto profissionais e empresariais quanto institucionais, compondo um cenário multifacetado e de alta complexidade que mereceria um artigo todo voltado apenas para investigação dessa atividade.

\section{OPEN ACCESS E 0 DIREITO AUTORAL}

$\mathrm{Na}$ perspectiva desse trabalho, considera-se necessário delinear alguns aspectos históricos e conceituais sobre a questão dos direitos autorais, uma vez que ambos os conceitos de Direitos Autorais e o Acesso Aberto se relacionam sobremaneira com a questão do uso de obras de autor em várias dimensões - ética e moral, profissional, econômica e acadêmica - da vida social. Não se pretendeu, por meio desse tópico, esgotar a questões existentes no tema e, sim, explorar um pouco do cenário pelo qual o direito autoral e a liberdade do autor têm se conduzido.

Tratando um pouco de seu percurso histórico, Gandelman (2007) observa que na era Clássica (e medieval), o direito autoral era visto como uma sanção moral, ou seja, o direito a autoria era reconhecido, sem, no entanto, ser remunerado (quem recebia pelo trabalho de transcrição do material eram os copistas). No século XV, a partir da invenção de Gutenberg: os direitos de impressão e comercialização das obras eram, geralmente, concedidos (por governantes) aos editores e não aos autores, pressupondose que os primeiros detinham autorização dos citados em segundo.

Os conceitos chave de outras línguas, relacionados ao Direito Autoral são:

- Copyright: nascida na Inglaterra, a Copyright Act (1709) foi uma lei outorgada na regência da Rainha Ana, pela qual a coroa concedia uma regalia (direito de royalties) por cópias impressas de determinadas obras, vigente por 21 anos a partir do registro formal da obra. O Licensing Act (1662) já proibia a impressão de qualquer livro não licenciado ou registrado.

- Droit d'auter: nascida na França (1791) em consequência dos princípios instaurados pela Revolução Francesa (1789), protegendo como direito do autor o conceito de ineditismo, paternidade e integridade de sua obra, os entendendo como direito morais inalienáveis e irrenunciáveis, além 
dos direitos patrimoniais (transferidos para seus herdeiros e sucessores legais).

No Brasil, a expressão Direito Autoral foi adotada sob um regime que vai de 1827 a 1917, pela instauração de leis que regiam a questão de forma episódica e incompleta, finalizando, em 1917, com a caracterização do Direito Autoral como uma espécie de propriedade "literária, científica e artística". Em 1973, foi transposta a maioria dos pontos da lei anterior, mantendo-se, por essa razão, a perda de autonomia legislativa, ou seja, sua não caracterização como um direito civil.

Através dos Tratados Internacionais, o Brasil aderiu ao princípio de Reciprocidade, pelo qual: "[...] se busca dar aos autores e titulares dos países aderentes aos convênios a mesma proteção legal que cada país dá ao seu autor ou titular nacional." (GANDELMAN, 2007, p. 31). Também se pode listar uma série de Convenções, com as devidas datas de promulgação: Berna (1975), Universal (1975), Roma (1965), Genebra (1975), culminando em 1994 com o Acordo sobre Aspectos dos Direitos de Propriedade Intelectual Relacionados ao Comércio (TRIPS) (inclusa a proteção de programas de computadores).

Pela Lei do Direito Autoral, o Sujeito (autor, titular da autoria da obra intelectual) e o objeto do direito autoral (a proteção legal da obra, independente do suporte físico ou veículo material que venha a utilizar), possui o aspecto moral que: "[...] garante ao criador o controle à menção de seu nome na divulgação de sua obra e o respeito a sua integridade, além dos direitos de modificá-la ou retirá-la de circulação [...]" (GANDELMAN, 2007, p. 33) e o aspecto patrimonial que: “[...] visa regular as relações jurídicas da utilização econômica das obras intelectuais." (GANDELMAN, 2007, p. 33).

No que se refere a iniciativas que tentam proteger os direitos autorais no ciberespaço, em âmbito internacional, se pode citar os contratos pioneiros no campo musical, a Internet Computer Agreement que propõe a licença para transmissão (distribuição) de obras via internet e a Experimental license Agreement for Computer Online Services, Eletronic Bulletin Boards, internet sites and similar operations. Segundo Zanini (2011) esses "Tratados de Internet", são instrumentos internacionais vinculados à utilização de obras protegidas pelo direito de autor no ambiente digital, não sendo o Brasil signatário de nenhum dos dois, apesar de ter participado das negociações diplomáticas que os aprovaram em 1996. O autor observa que o posicionamento do Brasil está fulcrado em uma estratégia de negociar somente até o patamar do TRIPS e não do TRIPS-plus (caso dos referidos tratados).

Considera-se que a questão do Marco civil da internet no Brasil é um tema relevante, no entanto, de grande profundidade, necessitando um artigo inteiramente destinado à análise do mesmo, sendo, portanto, abortado seu aprofundamento enquanto questão essencial a ser tratada nesse trabalho.

0 tratado da OMPI (Organização Mundial de Propriedade Intelectual) relacionado diretamente ao Direito de autor, ainda não incorporado à legislação, é o TODA (WCT) (Tratado sobre direitos do autor) que, segundo Cruz (2012), inova trazendo o reconhecimento dos direitos morais do autor, a consideração de que a ação de armazenamento da obra no formato digital é 
definido como ação de reprodução, assim como, sua disponibilização sem autorização prévia do autor - por possibilitar seu acesso indiscriminado - é entendida como violação do direito autoral.

Não se pode deixar de salientar que nessa situação de complexidade o copyright se tornou um negócio valioso no contexto contemporâneo de produção cultural. Segundo Smiers (2006), no mundo globalizado, o direito de autor incorpora-se como um negócio administrado pela tendência em fixar controle sobre bens culturais através de fusões que possibilitam acesso, manipulação e "domínio" dos componentes "autoria" e "obra", impondo como lógica do entretenimento atual a oferta reduzida e, consequentemente, consumo exacerbado de produtos-patrimônios de empresas.

Bacarat (2012) assevera que movimentos como os de Open Access (Acesso Aberto) funcionam em sinergia absoluta com a solução dos desafios oriundos da complicada gama de elementos atrelados ao Direito Autoral, pois: "[...] não entram em conflito com as leis de direitos de autor, pelo contrário, elas complementam a lei de forma prática." (p. 128). Nesse ponto, sua afirmação faz eco à preconização de coerência feita por Gandelman (2007) ao tratar a necessidade de intervenção e controle do Direito Autoral:

A Proteção correta dos espaços no ciberespaço virá da conjugação da lei pública com as ferramentas inventadas pela própria tecnologia, tal como no mundo real se protegem, por exemplo, os sítios e terrenos com legislação imobiliária e também com cercados de arame, e assim por diante. (p. 240).

O Open Access é entendido nesse trabalho, em consonância com os dois últimos autores citados, como uma ferramenta que possibilita por sua própria condição de ferramenta tecnológica que instaura, pela livre adesão do autor, um código que condiciona o documento sob sua insígnia a ser tratado dentro de parâmetros preestabelecidos, limitando seu uso conforme uma nomenclatura por ele utilizada, definida pelo próprio autor.

No intuito de finalizar esse tópico, inserindo já a questão fundamental desse trabalho - a situação de uso aberto de obras publicadas em revistas científicas, contraditoriamente categorizadas como de direito autoral transferido para as citadas revistas -, torna-se a utilizar o trabalho de Bacarat (2012), pelo qual se dimensiona a questão do Direito Autoral em relação ao Open Access, tidos ambos como instrumentos complementares na condução dos temas, asseverando, no entanto, que:

Os direitos autorais no campo científico deveriam ser tratados de forma distinta, uma vez que, na maioria dos casos, os pesquisadores de universidades e centros já recebem algum tipo de remuneração e não lucram com a publicação do artigo. Entretanto, o lucro vem do status garantido pelo direito moral. (p. 133). 


\section{PROCEDIMENTOS METODOLÓGICOS DO ESTUDO}

Com a finalidade de testar nossa hipótese de que não existe clareza acerca dos direitos autorais e de reuso, mesmo em revistas de Acesso Aberto, e para atender nossos objetivos, realizamos um estudo de caso, de caráter exploratório, durante o mês de fevereiro de 2014, com uma amostra de títulos das áreas de Ciências da Saúde e Ciências Biológicas disponibilizados pela plataforma SciELO-Brasil. De acordo com Severino (2007, p. 121), o estudo de caso pode ser definido como:

Pesquisa que se concentra no estudo de um caso particular, considerado representativo de um conjunto de casos análogos, por ele significativamente representativo. A coleta de dados e sua análise se dão da mesma forma que nas pesquisas de campo, em geral. 0 caso escolhido para a pesquisa deve ser significativo e bem representativo, de modo a ser apto a fundamentar uma generalização para situações análogas, autorizando inferências.

Seguindo as recomendações do Gil (2010), elaboramos um protocolo para a condução da etapa empírica de coleta de dados, realizada a partir da visita às webpáginas do conjunto dos sites relevantes ao estudo, a saber: DOAJ, SciELO (capa de cada revista), e o site de cada revista (na página em que se verificou publicada sua política editorial). A amostragem para os casos envolveu o levantamento de títulos de periódicos correntes das áreas de Ciências da Saúde e Ciências Biológicas no site do SciELO, o que correspondeu a um total de 117 títulos de periódicos correntes, tendo sido eliminados os títulos duplicados (em torno de 4) nas duas listas, perfazendo o total anteriormente informado.

Após este levantamento, conferiu-se quais desses periódicos levantados do SciELO estavam indexados no DOAJ, usando-se a ferramenta de busca no site do DOAJ que permite buscar apenas títulos de revistas científicas, do mundo todo, consideradas de Acesso Aberto.

Além disso, foi checado, na página da capa de cada revista (ou sob a opção de menu "sobre nós", da mesma) - disponibilizados pela plataforma SciELO -, se o conteúdo da revista é inserido sob uma licença aberta ou não já que no DOAJ esta informação nem sempre constava no registro da revista.

A última checagem realizada foi na seção da revista chamada "Instruções aos autores", utilizando-se na expressão de busca, às vezes por extenso, os termos "copyright", “direitos", “autorais", “cessão", "termo", "reservar", "reservados" - e seus equivalentes em inglês, quando as instruções para os autores eram dadas nesse idioma.

Todos os dados levantados foram inseridos numa planilha do software Microsoft Excel para a padronização, subsequente manipulação e análise estatística simples. 


\section{APRESENTAÇÃO E ANÁLISE DOS RESULTADOS}

A seguir, são apresentados alguns dos resultados quantitativos levantados, a partir das ponderações e interpretações iniciais em relação ao objetivo principal, determinado no início da pesquisa, ou seja: identificar o grau de "abertura" de revistas científicas de Acesso Aberto das áreas Ciências Biológicas e Ciências de Saúde hospedadas na plataforma SciELO-Brasil.

A seguir, na Tabela 1, são apresentados dados relacionados à amostra trabalhada.

Tabela 1: Detalhes da amostra das revistas científicas de Acesso Aberto hospedadas na plataforma SciELO-Brasil

Títulos

\begin{tabular}{c|c|c|c}
\cline { 2 - 4 } Área de publicação & No SciELO & \multicolumn{2}{|c}{ No DOAJ } \\
\cline { 2 - 4 } & Correntes & Registrados & Não registrados \\
\hline Ciências da Saúde & 91 & 83 & 8 \\
\hline Ciências Biológicos & 26 & 23 & 3 \\
\hline Total & 117 & $\mathbf{1 0 6}$ & 11
\end{tabular}

Fonte: Os autores.

Focando-se a análise exclusivamente nos 106 títulos que estão cadastrados no DOAJ - pois o fato de estarem indexados nesse Diretório significa que os avaliadores do DOAJ entendem que esses títulos satisfazem os critérios para serem considerados como revistas de Acesso Aberto -, realizou-se um levantamento da Política Editorial das revistas, no que diz respeito ao quesito Propriedade Intelectual em cada um dos títulos em questão.

Todos os títulos examinados, sem exceção, a partir da sua página de capa na plataforma SciELO-Brasil, da opção de menu "Sobre nós" e depois, sob a seção "Propriedade Intelectual", explicitavam que: "Todo o conteúdo do periódico, exceto onde está identificado, está licenciado sob uma Licença Creative Commons do tipo atribuição BY-NC. Entende-se que esta informação explicitada tem como forma uma "frase padrão" utilizada pelo SciELO para todos os títulos de periódicos hospedados na sua plataforma, evidenciando em sua comunicação aos leitores e usuários do ambiente a sua adesão automática aos princípios de Acesso Aberto, princípios estes aplicados em relação ao reuso do material disponibilizado pelo SciELO.

Considera-se relevante lembrar aqui que o Creative Commons (CC) é uma organização global, sem fins lucrativos, que tem como objetivo deixar os autores e criadores livres para determinarem sob quais termos e condições suas obras poderiam ser utilizadas, assim como quais direitos cederiam e sob quais condições o fariam, tendo como opções um espectro de licenças abertas.

Como Silva e Lara (2011) observam, diferentemente do sistema tradicional/legal de proteção dos direitos autorais, cujo dogma pode ser 
encapsulado na frase "todos os direitos reservados", as licenças CC reconhecem a possibilidade de que nem todo autor queira reservar todos os direitos para si, ou seja, dão aos autores a liberdade de escolherem pela situação de terem "alguns direitos reservados".

Si en el sistema del derecho de autor el principio es que toda utlización de una obra debe tener um permiso expresso del titular de los derechos de autor, em el caso de las licencias CC el princípio es que dicho permiso há sido entregado de antemano por el titular (SILVA; LARA, 2011, p. 18).

Não há espaço nesse artigo para se versar sobre todos os tipos de licenças CC existentes (que podem ser consultadas em http://creativecommons.org.br/as-licencas/), mas considera-se pertinente observar que a licença CC BY-NC, identificada nos periódicos SciELO, permite que:

[...] outros remixem, adaptem, e criem obras derivadas sobre a obra licenciada, sendo vedado o uso com fins comerciais. As novas obras devem conter menção ao autor nos créditos e também não podem ser usadas com fins comerciais, porém as obras derivadas não precisam ser licenciadas sob os mesmos termos desta licença (CREATIVE COMMONS BRASIL, 2014).

Desse modo, a opção por uma licença CC pelo criador, autor ou instituição responsável pela publicação, comunica aos usuários do conteúdo ao qual a licença se aplica, qual uso estes poderão fazer, legitimamente, desse conteúdo. Como se percebe da definição citada acima, a licença CC BY-NC é uma das licenças mais flexíveis e abertas, tendo-se por referência a licença BY, a mais flexível, pois exige apenas a atribuição/reconhecimento de autoria da obra, deixando para o usuário uma grande liberdade para reutilizar o trabalho.

No entanto, quando se observa o quesito Direito Autoral na amostra, tendo por referência o autor, a situação parece ser bastante distinta, pois, mesmo que, como já foi dito, todos os títulos do SciELO-Brasil, aqui analisados, foram identificados como portadores das licenças CC BY-NC, ao se submeter um artigo ao periódico, na maior parte das vezes, os próprios autores têm que assinar um termo de cessão dos direitos autorais da obra - o que aponta, na visão desse trabalho, uma contradição.

A Tabela 2 apresenta mais alguns dados levantados no breve estudo apresentado por esse trabalho: 
Tabela 2: Periódicos da plataforma SciELO que exigem cessão de Direitos Autorais

\begin{tabular}{c|c|c|c|c|c}
\multirow{2}{*}{$\begin{array}{c}\text { Área de } \\
\text { publicação }\end{array}$} & $\begin{array}{c}\text { Correntes no } \\
\text { SciELO e } \\
\text { indexados no } \\
\text { DOAJ }\end{array}$ & $\begin{array}{c}\text { Com Licença } \\
\text { CC BY-NC }\end{array}$ & \multicolumn{2}{|c}{ Cessão de Direitos Autorais } \\
\cline { 4 - 6 } & 83 & 83 & $65(78 \%)$ & 4 & \multicolumn{2}{|c}{$\begin{array}{c}\text { Não } \\
\text { Que não } \\
\text { exigem }\end{array}$} & 14 \\
\hline $\begin{array}{c}\text { Ciências da } \\
\text { Saúde }\end{array}$ & 23 & 23 & $9(39 \%)$ & 4 & 10 \\
\hline $\begin{array}{c}\text { Ciências } \\
\text { Biológicas }\end{array}$ & $\mathbf{1 0 6}$ & $\mathbf{1 0 6}$ & $\mathbf{7 4}$ & $\mathbf{8}$ & $\mathbf{2 4}$
\end{tabular}

Fonte: Os autores.

A Tabela 2 mostra que $78 \%$ das 83 revistas da área de Ciências da Saúde cadastradas no DOAJ - que, lembramos, adere aos princípios mais característicos de Acesso Aberto - exigem que os autores dos artigos assinem um termo de cessão dos direitos autorais. Na área de Ciências Biológicas esta porcentagem é de $39 \%$ das 23 revistas no DOAJ.

Observa-se que, ao ceder os direitos autorais à revista científica, o(s) autor(es), basicamente, transfere à revista, ou à instituição responsável pela revista, direitos exclusivos do direito patrimonial que a lei confere ao titular (autor): isto é, os direitos patrimoniais são transferíveis (diferentemente dos direitos morais). Dentre os direitos patrimoniais se incluem, entre outros, o direito de distribuição, adaptação, tradução, a disseminação pública (por exemplo, na internet), ou publicação (SILVA; LARA, 2011), englobando, também, o impedimento do direito de posterior utilização pelo autor, inclusive de seu depósito num repositório digital (MELERO, 2010), por exemplo.

Os termos de cessão dos direitos autorais empregados por estas revistas em Acesso Aberto no SciELO, registrados no DOAJ, englobam desde a "mera" transferência de copyright do(s) autor(es) para a revista, permitindo, às vezes, à revista a "reprodução do todo ou em parte desde que mencionadas as fontes", ou, até mesmo, de forma mais abrangente e conservadora, a transferência de todos os direitos, que passam a ser "propriedade exclusiva" da revista, vedando-se a reprodução parcial ou total sem a devida autorização da "proprietária".

Essa situação pode ser observada no caso de um título da área de saúde, gerenciado e veiculado numa revista a partir da plataforma do Open Journal System (OJS) do Public Knowledge Project, mas indexada e acessível a partir do SciELO. O conteúdo do título em questão está licenciado sob a licença CC BY 3.0 (bastante aberta), no entanto, seu termo de cessão de direitos autorais é bastante rígido, como visto no trecho a seguir (no qual o termo "cedente" se refere ao autor e o termo "cessionária" corresponde à revista):

3. O CEDENTE cede e transfere todos os direitos autorais relativos à OBRA à CESSIONÁRIA, especialmente os direitos de edição, de publicação, de tradução para outro idioma e de reprodução por qualquer processo ou técnica. A CESSIONÁRIA passa a ser proprietária exclusiva dos direitos referentes à OBRA, sendo vedada qualquer reprodução, total ou parcial, em qualquer outro meio de divulgação, impresso ou eletrônico, sem que haja prévia autorização 
escrita por parte da CESSIONÁRIA (VIGILÂNCIA SANITÁRIA EM DEBATE, 2014).

Há certa contradição na aplicação de termos de cessão de direitos deste teor tendo em paralelo a utilização de licenças abertas como as do CC; isto é considerado contraditório, sobretudo, levando-se em consideração o ponto de vista do usuário que pressupõe permissões de uso flexíveis, mas, do ponto de vista dos autores, as permissões de uso de seu próprio texto são bastante restritivas.

A última coluna da Tabela 2 contém dados referentes àquelas políticas editoriais que não explicitam no corpo do texto das suas páginas quais direitos o autor pode continuar detendo após ter seu artigo publicado no periódico. Evidentemente, o fato de não explicitar a política adotada nessa questão, não implica a aceitação, por parte da revista, de que o autor se manterá detentor dos seus direitos autorais.

Pois há que se observar que justamente nesses periódicos - como é o caso da maioria das revistas científicas online da atualidade - o processo de submissão do manuscrito é inteiramente automatizado, consistindo de vários passos em que o autor fornece informações, aceitando as condições impostas pelas revistas, tendo, às vezes, que restringir suas ações, "ticando" caixinhas que lhe concedem ou não a finalização do processo, e é comum que nesses procedimentos automatizados o autor acabe tendo que aceitar a cessão dos direitos autorais à revista. Existe a possibilidade, então, que estas 24 revistas requeiram, sim, a cessão dos direitos autorais, mas infelizmente, não houve tempo neste estudo para realizar testes (ou seja, de passar por todas as etapas de uma submissão online) para comprovar ou refutar essa hipótese.

No que tange às políticas editorais adotadas pelas 8 revistas das duas áreas que não exigem, explicitamente, a cessão dos direitos autorais, pode se afirmar que representam políticas editorais de revistas científicas que entendem, de modo mais "holístico" e coerente, as implicações de se nomearem revistas de Acesso Aberto, que são hospedadas, divulgadas e acessadas a partir da plataforma SciELO, indexadas, dentre outros índices, pelo DOAJ. Pode se exemplificar este procedimento, na área das Ciências Biológicas, com duas revistas:

- Journal of Venomous Animals and Toxins including Tropical Diseases: declara, claramente, que "O copyright fica com os autores", remetendo-os ao site da Editora (Publisher) em Acesso Aberto - o BioMed Central - para maiores detalhes, onde está claramente explicado (em inglês, disponível em: http://www.biomedcentral.com/about/license/ ) o quê o autor e usuário do artigo podem fazer com o artigo;

- Ambiente \& Sociedade: pode se afirmar que é a revista mais aberta encontrada entre os títulos das duas áreas analisadas, encapsulando algumas qualidades ideais de uma política editorial, posto que, ao mesmo tempo em que informa os autores sobre o que implica aceitar uma licença CC, elucida também alguns princípios e vantagens de Acesso Aberto.

Considera-se pertinente citar o texto integral, conforme disponibilizado pela revista:

Autores que publicam neste periódico concordam com os seguintes termos: 1 . Autores mantêm os direitos autorais e concedem ao periódico o direito de primeira publicação, 
com o trabalho simultaneamente licenciado sob a Licença Creative Commons Attribution que permite 0 compartilhamento do trabalho com reconhecimento da autoria e publicação inicial neste periódico. 2. Autores têm autorização para assumir contratos adicionais separadamente, para distribuição não exclusiva da versão do trabalho publicada neste periódico (ex.: publicar em repositório institucional ou como capítulo de livro), com reconhecimento de autoria e publicação inicial neste periódico. 3. Autores têm permissão e são estimulados a publicar e distribuir seu trabalho online (ex.: em repositórios institucionais ou na sua página pessoal) a qualquer ponto antes ou durante o processo editorial, já que isso pode gerar alterações produtivas, bem como aumentar o impacto e a citação do trabalho publicado (Veja $\underline{0 \text { Efeito }}$ do Acesso Livre). (AMBIENTE \& SOCIEDADE, 2014).

Em relação ao espectro de graus de abertura de revistas e textos em Acesso Aberto, apresentados no supramencionado panfleto HowOpenIsIt?, a revista Ambiente \& Sociedade - por ser clara e explicitamente aberta na sua política editorial, não deixando dúvidas para usuários e autores sobre a liberdade que estes têm de fazerem uso do texto pós-publicação - se posiciona, indubitavelmente, no lado "mais aberto" desse espectro.

Entre as poucas (quatro) revistas na área de Ciências de Saúde que não mencionam, explicitamente, a necessidade do(s) autor(es) cederem os direitos autorais, pode ser citada a Brazilian Dental Journal que, em sua página de política editorial e instruções aos autores, em nenhum momento, utiliza os termos copyright ou direitos autorais. Observa-se, também, que a submissão do manuscrito não é automatizada e, sim, por envio "manual" do autor para um e-mail. Ainda em tempo, na página de capa da Brazilian Dental Journal é mostrado quem são os órgãos patrocinadores da revista, que incluem CNPq, CAPES, MEC e MCT. Assim, seria fato surpreendente se a revista operasse, com respeito à questão de direitos autorais, sob um regime mais fechado e conservador, já que esses órgãos do governo brasileiro estimulam a adoção de iniciativas que fomentem a disponibilização dos resultados da ciência brasileira em canais de Acesso Aberto, sobretudo na área de saúde.

\section{CONSIDERAÇÕES FINAIS}

Este estudo representou uma forma de testar a suposição, intuída a partir de conversas informais e entrevistas realizadas com pesquisadorescientistas no decorrer de outras duas pesquisas sobre o conceito de Acesso Aberto, a saber: que ainda existe desconhecimento e confusão em torno do termo "Acesso Aberto"; e que estas confusões podem se manifestarem em políticas editorais de revistas de Acesso Aberto.

As contradições em torno das políticas de Direitos Autorais/direitos de uso dos trabalhos publicados pelas revistas aqui examinadas foram 
localizadas, principalmente, no fato de que ao mesmo tempo em que todas as revistas, sem exceção, operam sob uma licença Creative Commons BY-NC, a maioria delas também exige que os autores dos artigos transfiram os Direitos Autorais às revistas. Considera-se pertinente esclarecer aqui que não existe uma regra que dite que revistas em Acesso Aberto não podem ser os detentores de tais direitos só por ser de Acesso Aberto, mas também há necessidade de se observar a situação decorrente de quando um usuário (leitor) dessas revistas vê que o título carrega uma licença CC BY ou CC BY$\mathrm{NC}$, deduzindo possuir a liberdade de fazer certas coisas com este texto que essa licença aberta lhe confere.

É importante reconhecer que o usuário-leitor não tem obrigação de procurar se o título em questão obrigou ao autor a cessão de seus direitos, sobretudo se estas obrigações se encontram baixo as "instruções aos autores" e se dirigem ao autor, não ao usuário-leitor. No entanto, há de se reconhecer que o tom da redação utilizada em muitos desses termos de concessão dos Direitos Autorais é, sim, bastante rígida e legalista, não deixando muita margem de interpretação equivocada para os autores assiná-los. Nesse ponto do processo se identifica a confusão: o usuário-leitor apenas vê que o título é licenciado sob uma licença flexível de CC, mas, ao mesmo tempo, o autor foi obrigado a assinar um termo de cessão dos seus direitos. Quem teria maiores direitos de reuso e divulgação do artigo em repositórios, entre outros canais?

De acordo com o espectro de "abertura" de documentos e revistas apresentado no panfleto HowOpenIsIt? ("Quão aberto é?") lançado em 2011 por SPARC, PLoS e OASPA, as revistas de Acesso Aberto aqui analisadas se localizam na parte do espectro mais aberto ao se falar dos direitos de reuso pelos usuários, mas ao mesmo tempo, a maioria delas também, e simultaneamente, se localiza apenas a um passo do ponto no espectro que marca a posição mais fechada no que diz respeito aos Direitos Autorais, então detidos pela Editora (Publisher).

Acredita-se, inclusive pela pesquisa aqui descrita, que o copyright é um importante instrumento de qualificação de trabalhos científicos, e que não são utilizados de forma adequada, talvez por falta de conhecimentos profundos de suas diretrizes, ou antes, por um temor - principalmente por parte das revistas científicas - do Acesso Aberto não ser suficientemente "legalizado" para isenção da exigência de um documento complementar praxe no momento de submissão de artigos - que expresse "formal e legalmente" a transferência (liberação de uso) dos direitos de autor do trabalho científico então submetido.

A não adequação desse procedimento é observada, sobretudo, por questões:

- De reuso do trabalho submetido: nas condições legais estipuladas pela Lei de Direito Autoral na transferência de direitos, se impede, tecnicamente, que inclusive o próprio autor administre essa transferência passando a ser considerado pela leitura literal do regimento, indivíduo submetido às sanções legais de reprodução da obra sem autorização da revista (atual detentora);

- De duplicação contraditória: isso porque, das revistas analisadas a maioria apresenta selo de autenticação de licença Creative Commons, o que já condiciona que os autores que submetem seu trabalho no site estejam cientes 
e em concordância com a liberação de sua obra na condição de Acesso Aberto, tornando desnecessário, pela visão dessa pesquisa, a expressão de liberação (transferência) do objeto à revista.

Nota-se, no entanto, que existem exceções de uso desses procedimentos mencionados como inadequados, pelo menos no corpus utilizado por esse trabalho, o que aponta possibilidades de adequação do Open Access como chave única e integradora do campo da publicação científica na questão do processo de legitimação do uso do texto autoral.

Por fim, pode ser concluída que ainda existe necessidade de maiores esclarecimentos com editores de revistas em Acesso Aberto sobre o que, exatamente, esta modalidade de publicação implica, e deveria implicar, tanto para os usuários-leitores, quanto para os autores, para que as políticas editoriais dessas revistas possam ser cada vez mais coerentes e assim, trabalhar em prol da circulação e alcance de novas pesquisas no campo científico brasileiro.

\section{REFERÊNCIAS}

AMBIENTE \& SOCIEDADE. Declaração de direito autoral. Disponível em: $<$ http://submission.scielo.br/index.php/asoc/about/submissions\#onlineSub

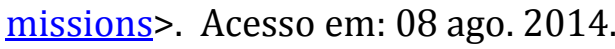

BACARAT, A. C. 0 significado do direito autoral na era da sociedade da informação: um estudo comparado de convenções internacionais. $148 \mathrm{f}$. Dissertação (Mestrado em Ciência, Tecnologia e Sociedade)- Universidade Federal de São Carlos, São Carlos, 2012.

CREATIVE COMMONS BRASIL. 0 que é CC? Disponível em: <http://creativecommons.org.br/o-que-e-o-cc/>. Acesso em: 02 ago. 2014.

CRUZ, R. S. A tutela dos direitos autorais na idade mídia e a garantia da liberdade de acesso à informação no âmbito internacional. In: CONGRESSO INTERNACIONAL DE DIREITO E CONTEMPORANEIDADE. 1., 2012. Santa Maria. Anais... Santa Maria: Universidade Federal de Santa Maria, 2012. Disponível em: <http://coral.ufsm.br/congressodireito/anais/2012/9.pdf >. Acesso em: 21 fev. 2013.

DIRECTORY OF OPEN ACCESS JOURNALS-DOAJ. 2014. Disponível em: <http://doaj.org/oainfo>. Acesso em: 20 mar. 2015.

FERREIRA, S. M. S. P.; TARGINO, M. G. Preparação de revistas científicas: teoria e prática. São Paulo: Reichmann \& Autores, 2005.

GIL, A. C. Como elaborar projetos de pesquisa. 5. ed. São Paulo: Atlas, 2010.

GANDELMAN, H. De Gutemberg à internet: direitos autorais das origens à era digital. Rio de Janeiro: Editora Record, 2007. 
GUIBAULT, L. Owning the right to open up access to scientific publications. In: GUIBAULT, L.; ANGELOPOULOS, C. Open content licensing: from theory to practice. Amsterdam: Amsterdam University Press, 2011. p. 137-168.

MELERO, R. Guia prática sobre los derechos partrimoniales o de explotación (copyright) y su relación con el auto-archivo en repositorios de Acesso Aberto. [S.l.]: [s.n.], 2010. Disponível em: <http://www.accesoabierto.net/es/bibliografia/guia-practica-sobre-losderechos-patrimoniales-o-de-explotacion-copyright-y-su-relacion $>$. Acesso em: 04 ago. 2014.

MONBIOT, G. The lairds of learning. The Guardian, London, 30 Ago. 2011. Disponível em: <http://www.monbiot.com/2011/08/29/the-lairds-oflearning/>. Acesso em: 01 ago. 2014.

MORRISON, H. Scholarly communication for librarians. Oxford: Chandos, 2009.

PACKER, A. The SciELO open access: a gold way from the south. Canadian Journal of Higher Education, v. 39, n. 3, p. 111-126, 2009.

RODRIGUES, E. Acesso livre ao conhecimento: a mudança do sistema de comunicação da ciência e os profissionais de informação. Cadernos de Biblioteconomia, Arquivística e Documentação, Lisboa, n. 1, p. 24-35, 2004.

SEVERINO, A. J. Metodologia do trabalho científico. 23. ed. São Paulo: Cortez, 2007.

SHERPA-RoMEO. Políticas de copyright e de auto-arquivo de editores. Disponível em: <http://www.sherpa.ac.uk/romeo/search.php>. Acesso em: 20 mar. 2015.

SILVA, A. C.; LARA, C. Políticas Editoriales de Publicaciones Académicas en Línea en Latinoamérica. Santiago: Derechos Digitales, 2011. Disponível em: <http://www.revistasabiertas.com/wp-content/uploads/InformePoliticas Editoriales de Publicaciones.pdf>. Acesso em: 04 ago. 2014.

SMIERS, J. As artes sob pressão: promovendo a diversidade cultural na era da globalização. São Paulo: Escritura Editora; Instituto Pensante, 2006.

SUBER, P. Open Access. Cambridge: MIT Press, 2012.

SUBER, P.; SUTTON, C. Society publishers with open access journals. SPARC Open Access Newsletter, n. 115, November 2, 2007. Disponível em: $<$ http://dash.harvard.edu/bitstream/handle/1/4387568/suber societies.ht ml? sequence=1>. Acesso em: 20 mar. 2015.

VIGILÂNCIA SANITÁRIA EM DEBATE. Declaração de direito autoral. Disponível em: 
$<$ https://visaemdebate.incqs.fiocruz.br/index.php/visaemdebate/about/sub missions\#copyrightNotice>. Acesso em: 15 jul. 2014.

ZANINI, L. E. A. A proteção internacional do direito de autor e o embate entre os sistemas do copyright e do droit d'auteur. Revista da Seção Judiciária do Rio de Janeiro, Rio de Janeiro, v. 18, n. 30, p. 115-130, 2011. Disponível em: <http://www4.jfrj.jus.br/seer/index.php/revista sjrj/article/viewFile/242/ 231>. Acesso em: 20 mar. 2015.

Editor do artigo: Adilson Luiz Pinto 